\title{
Effects of IL-10 and glucose on expression of OPG and RANKL in human periodontal ligament fibroblasts
}

\author{
L. Zhang ${ }^{1 *}$, Y. Ding ${ }^{2 *}$, G.Z. Rao ${ }^{1}$ and D. Miao ${ }^{1}$ \\ ${ }^{1}$ Stomatology Hospital, Xi'an Jiaotong University College of Medicine, Xi'an, China \\ ${ }^{2}$ Wuxi Mental Health Center of Nanjing Medical University, Wuxi, China
}

\begin{abstract}
The effects of interleukin-10 (IL-10) and glucose on mRNA and protein expression of osteoprotegerin (OPG), and its ligand, receptor activator of nuclear factor- $\mathrm{B}$ ligand (RANKL), were investigated in human periodontal ligament fibroblasts (HPDLFs). Primary HPDLFs were treated with different concentrations of IL-10 $(0,1,10,25,50$, and $100 \mathrm{ng} / \mathrm{mL})$ or glucose $(0,5.5,10,20,30$, and $40 \mathrm{mmol} / \mathrm{L}$ ). Changes in mRNA and protein expression were examined using the reverse-transcription polymerase chain reaction (RT-PCR) and Western blot analysis, respectively. After IL-10 treatment, mRNA and protein levels of OPG were increased, while mRNA and protein levels of RANKL were decreased $(P<0.05)$, both in a concentration-dependent manner. Glucose stimulation had the opposite concentration-dependent effect to that of IL-10 on OPG and RANKL expression. IL-10 upregulated OPG expression and downregulated RANKL expression, whereas high glucose upregulated RANKL and downregulated OPG in HDPLFs. Abnormal levels of IL-10 and glucose may contribute to the pathogenesis of periodontal disease.
\end{abstract}

Key words: Human periodontal ligament fibroblasts; Interleukin-10; Glucose; Osteoprotegerin; Receptor activator of nuclear factor- $\kappa B$ ligand

\section{Introduction}

Osteoprotegerin (OPG) and its ligand, receptor activator of nuclear factor- $\kappa \mathrm{B}$ ligand (RANKL), are critical factors in regulating the differentiation and maturation of osteoclasts, as well as bone resorption (1). The equilibrium between OPG and RANKL activity has an essential role in the homeostasis of bone metabolism. In the pathological process of periodontal disease, the OPG/RANKL equilibrium is disrupted, leading to increased bone resorption $(2,3)$. Human periodontal ligament fibroblasts (HPDLFs) are the primary cell type in the periodontal ligament and they contribute to the integrity of the periodontium. HPDLFs express both OPG and RANKL, affecting the formation of osteoclasts by modulating the OPG/RANKL equilibrium (4).

Multiple cytokines, which have different effects on the expression of OPG and RANKL, are involved in the pathogenesis of periodontal disease (5). Interleukin (IL)10 is an important anti-inflammatory cytokine. It has been demonstrated that lack of IL-10 leads to more severe periodontal inflammation and further accelerates bone loss (6). However, the regulatory effect of IL-10 on the expression of OPG and RANKL has not yet been defined.

Diabetes is an endocrine and metabolic disorder that is caused by aberrant insulin function, leading to systemic bone metabolism disorders and osteoporosis (7). Diabetic patients with periodontal disease have severe periodontal destruction, progressive alveolar bone loss, and a poor prognosis $(8,9)$. These studies indicate that diabetesassociated hyperglycemia may contribute to the progression of periodontal disease. Furthermore, it has been suggested that low levels of IL-10 correlate with the pathogenesis of diabetes (10). The aim of this study was to explore the influence of IL-10 and elevated glucose concentrations on the expression of OPG and RANKL in HPDLFs.

\section{Material and Methods}

\section{Primary culture of HPDLFs}

This study was approved by the Human Ethics Committees of Xi'an Jiaotong University (Xi'an, China; approval number XAJTU-22). Written informed consent was obtained from all study participants. HPDLFs were isolated from six clinically normal premolar teeth during orthodontic treatment (11). The teeth were placed in sterile D-Hanks solution containing ampicillin $(200 \mu \mathrm{g} / \mathrm{mL})$ and sulfuric streptomycin $(200 \mu \mathrm{g} / \mathrm{mL})$, and washed. Periodontal tissues were scraped from the middle one-third of the teeth roots, cut into pieces in

Correspondence: L. Zhang: <lanzhang@xjtu.edu.cn> | Y. Ding: <dingyanwx@gmail.com>

*These authors contributed equally to this study.

Received May 12, 2015 | Accepted September 8, 2015 
Table 1. Primers used in RT-PCR.

\begin{tabular}{ll}
\hline Genes & \multicolumn{1}{c}{ Primers } \\
\hline OPG (342 bp) & Forward: 5'-TCA AGC AGG AGT GCA ATC G-3' \\
& Reverse: 5'-AGA ATG CCT CCT CAC ACA GG-3' \\
RANKL (442 bp) & Forward: 5'-CGC CAG CAG AGA CTA CAC C-3' \\
& Reverse: 5'-TGA GCC ATC CAC CAT CGC-3' \\
$\beta$-actin (179 bp) & Forward: 5'-ATC GTG CGT GAC ATT AAG GAG AAG-3' \\
& Reverse: 5'-AGG AAG GAA GGC TGG AAG AGT G-3' \\
\hline
\end{tabular}

OPG: osteoprotegerin; RANKL: receptor activator of nuclear factor- $\mathrm{B}$ ligand; RT-PCR: reverse-transcription polymerase chain reaction.

Dulbecco's modified Eagle's medium (DMEM) without fetal bovine serum (FBS), and then centrifuged at $800 \mathrm{~g}$ for $5 \mathrm{~min}$ followed by supernatant removal. The periodontal tissue pellets were suspended in DMEM with $20 \%$ FBS, transferred to flasks coated by semi-dry FBS, and cultured under $5 \%$ $\mathrm{CO}_{2}, 37^{\circ} \mathrm{C}$, and saturated humidity (by inversion of the flasks). After $4 \mathrm{~h}$ of culture, $2 \mathrm{~mL}$ of DMEM with $20 \%$ FBS was added to the medium, and the flask was turned over gently for continued culturing. The medium containing $20 \%$ FBS was changed every 2-3 days. Cells from the fifth passage were seeded on coverslips in 12-well plates at a density of $10^{4}$ cells $/ \mathrm{mL}$ until $60 \%-70 \%$ confluence. After experimental treatments, the cells were stained with hematoxylin and eosin (H\&E), and cytochemistry analysis for vimentin and keratin was performed.

\section{IL-10 and glucose treatment}

HPDLFs were harvested, and then cultured in 25- $\mathrm{mL}$ flasks at a density of $5.0 \times 10^{5}$ cells $/ \mathrm{mL}$ in DMEM with $20 \%$ FBS until cells adhered to the flask at $80 \%$ confluence. The culture medium was replaced with DMEM without FBS for $24 \mathrm{~h}$ before experiments. HPDLFs were cultured in DMEM with 6 different concentrations of IL-10 and glucose for $24 \mathrm{~h}$. The concentrations of IL-10 were 0 , $1,10,25,50$, and $100 \mathrm{ng} / \mathrm{mL}(12)$, and the concentrations of glucose were $0,5.5,10,20,30$, and $40 \mathrm{mmol} / \mathrm{L}$ (13).

\section{RT-PCR analysis}

Total RNA was isolated from HPDLFs using Trizol kits according to the manufacturer's instructions. The absorbance at $260 \mathrm{~nm}$ (OD260) and $280 \mathrm{~nm}$ (OD280) was measured, and the purity of RNA was determined by the OD260/OD280 ratio. cDNA was generated from total RNA by RT-PCR. The PCR primers for OPG, RANKL and $\beta$-actin are listed in Table 1. PCR cycles were performed as follows: initial denaturation at $94^{\circ} \mathrm{C}$ for $3 \mathrm{~min}$, followed by 35 cycles of denaturation at $94^{\circ} \mathrm{C}$ for $15 \mathrm{~s}$, annealing for $30 \mathrm{~s}$ at the indicated temperatures, and extension for $60 \mathrm{~s}$ at $72^{\circ} \mathrm{C}$. The annealing temperature for OPG, RANKL, and $\beta$-actin was $55^{\circ} \mathrm{C}, 58^{\circ} \mathrm{C}$, and $55^{\circ} \mathrm{C}$, respectively. $\mathrm{PCR}$ products were visualized by agarose gel electrophoresis. The grey-scale value of each band was measured by the gel image analyzing system.

\section{Western blot analysis}

Cells were lysed with radio-immunoprecipitation assay (RIPA) buffer and protein concentrations were measured by the bicinchoninic acid (BCA) assay. Samples containing an equal amount of protein mixed with sample buffer were loaded into each well, resolved by $10 \%$ SDS-PAGE, and electroblotted onto polyvinylidene difluoride membranes. The membranes were blocked for $1 \mathrm{~h}$ at room temperature and incubated with primary antibodies at $4^{\circ} \mathrm{C}$ overnight, followed by appropriate horseradish peroxidase-conjugated secondary antibodies for $1 \mathrm{~h}$ at room temperature. After washing, the membranes were developed using a WestPico ECL kit (Pierce Chemical Co., USA). The following specific primary antibodies were used: mouse anti-OPG, anti-RANKL, and anti-glyceraldehyde-3-phosphate dehydrogenase (GAPDH) antibodies (Santa Cruz Biotechnology, USA).
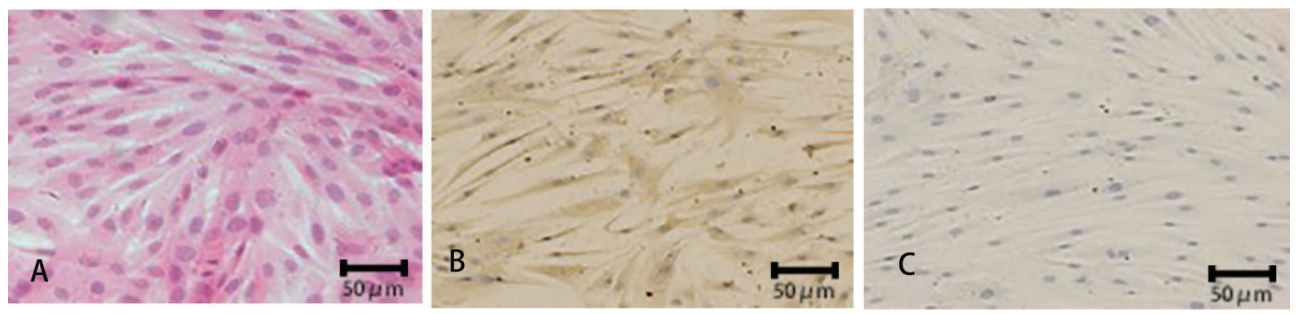

Figure 1. Characterization of human periodontal ligament fibroblasts (HPDLFs). H\&E staining $(A)$ and immunocytochemical staining for vimentin $(B)$ and keratin $(C)$ were performed in HPDLFs. Representative images are shown. 


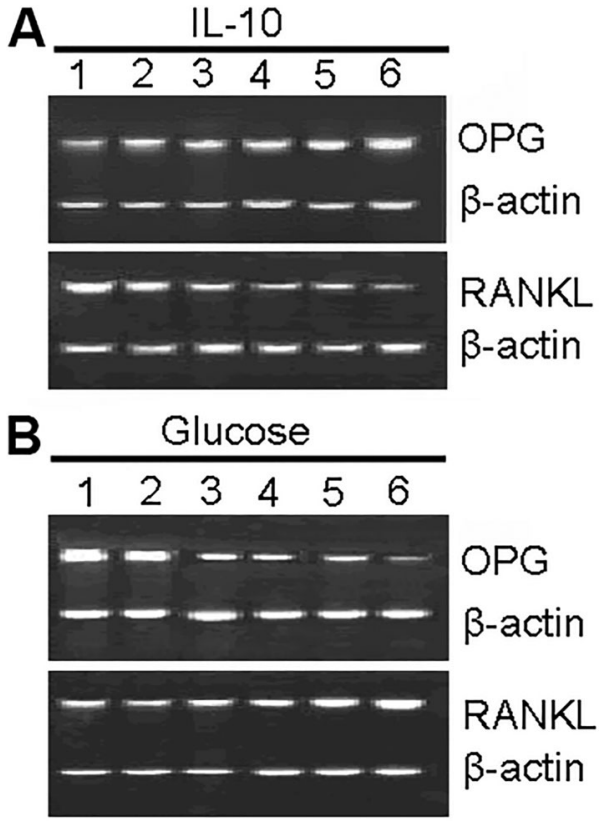

Figure 2. Effects of $\mathrm{IL}-10(A)$ and glucose $(B)$ at different concentrations on the mRNA expression of osteoprotegerin (OPG) and receptor activator of nuclear factor- $\mathrm{kB}$ ligand (RANKL) in human periodontal ligament fibroblasts. Panel $A$, lanes 1-6: cells treated with interleukin-10 (IL-10) at $0,1,10,25,50$, and $100 \mathrm{ng} / \mathrm{mL}$, respectively. Panel B, lanes 1-6: cells treated with glucose at $0,5.5,10,20,30$, and $40 \mathrm{mmol} / \mathrm{L}$, respectively.

\section{Statistical analysis}

Data were analyzed by one-way analysis of variance, followed by Tukey's multiple comparison. Results are reported as means $\pm S D$. Statistical analyses were performed using the SPSS 13.0 software package (SPSS Inc., USA). P-values of less than 0.5 were considered to be statistically significant.

\section{Results}

\section{Cell morphology}

Under the light microscope, $\mathrm{H} \& \mathrm{E}$ staining revealed that HPDLFs were spindle-shaped with several protrusions.
Plasma was stained pink with round or oval nuclear centers stained purple (Figure 1A). Immunocytochemistry showed positive cytoplasmic staining for vimentin (Figure 1B), but not keratin (Figure 1C).

\section{Effect of IL-10 and glucose on OPG and RANKL mRNA expression}

The effects of IL-10 and glucose on OPG and RANKL mRNA expression were determined by RT-PCR analysis (Figure 2). Table 2 shows the densitometric analysis of OPG and RANKL mRNA levels normalized against $\beta$-actin. Compared with untreated cells, IL-10 treatment upregulated OPG mRNA expression and downregulated RANKL mRNA expression $(P<0.05)$, with both changes occurring in a concentration-dependent manner. At normal physiological concentration $(5.5 \mathrm{mmol} / \mathrm{L})$, glucose had only a mild effect on mRNA expression of OPG and RANKL. However, at higher concentrations (10-40 mmol/L), glucose reduced mRNA levels of OPG and increased mRNA levels of RANKL ( $P<0.05$ for both).

\section{Effect of IL-10 and glucose on OPG and RANKL protein expression}

Western blot analysis was conducted to examine the effects of IL-10 and glucose on OPG and RANKL protein expression (Figure 3 ). Table 3 presents the densitometric analysis of Western blots. Similar to the mRNA findings, high IL-10 and glucose concentrations had opposing effects on the protein expression of OPG and RANKL.

\section{Discussion}

Periodontal disease and diabetes are both prevalent disorders (14). Epidemiological studies indicate that periodontal disease and diabetes share some common risk factors, and represent high risk factors for each other (15). The main biochemical characteristic of diabetes is elevated glucose levels, which play a significant role in the initiation and progression of this disease. High glucose levels have also been demonstrated to increase osteoclast activity, accelerate bone resorption, and cause aberrant bone metabolism (9). There is a close relationship between glucose levels and the

Table 2. Relative mRNA expression of osteoprotegerin (OPG) and receptor activator of nuclear factor- $\mathrm{KB}$ ligand (RANKL) in human periodontal ligament fibroblasts after interleukin-10 (IL-10) or glucose treatment.

\begin{tabular}{cccccc}
\hline IL-10 $(\mathrm{ng} / \mathrm{mL})$ & OPG & RANKL & Glucose $(\mathrm{mmol} / \mathrm{L})$ & OPG & $R A N K L$ \\
\hline 0 & $0.732 \pm 0.016^{\mathrm{a}}$ & $0.528 \pm 0.009^{\mathrm{a}}$ & 0 & $0.920 \pm 0.007^{\mathrm{a}}$ & $0.606 \pm 0.009^{\mathrm{a}}$ \\
1 & $0.883 \pm 0.009^{\mathrm{b}}$ & $0.512 \pm 0.007^{\mathrm{a}}$ & 5.5 & $0.930 \pm 0.009^{\mathrm{a}}$ & $0.610 \pm 0.012^{\mathrm{a}}$ \\
10 & $0.975 \pm 0.010^{\mathrm{c}}$ & $0.414 \pm 0.018^{\mathrm{b}}$ & 10 & $0.843 \pm 0.010^{\mathrm{b}}$ & $0.923 \pm 0.010^{\mathrm{b}}$ \\
25 & $1.135 \pm 0.015^{\mathrm{d}}$ & $0.342 \pm 0.010^{\mathrm{c}}$ & 20 & $0.770 \pm 0.019^{\mathrm{c}}$ & $1.218 \pm 0.018^{\mathrm{c}}$ \\
50 & $1.283 \pm 0.014^{\mathrm{e}}$ & $0.242 \pm 0.018^{\mathrm{d}}$ & 30 & $0.670 \pm 0.009^{\mathrm{d}}$ & $1.323 \pm 0.007^{\mathrm{d}}$ \\
100 & $1.345 \pm 0.016^{\mathrm{f}}$ & $0.206 \pm 0.019^{\mathrm{e}}$ & 40 & $0.475 \pm 0.015^{\mathrm{e}}$ & $1.473 \pm 0.016^{\mathrm{e}}$ \\
\hline
\end{tabular}

Data are reported as means $\pm S D$. Different superscript letters indicate significant differences $(P<0.05$; ANOVA followed by Tukey's multiple comparison). 


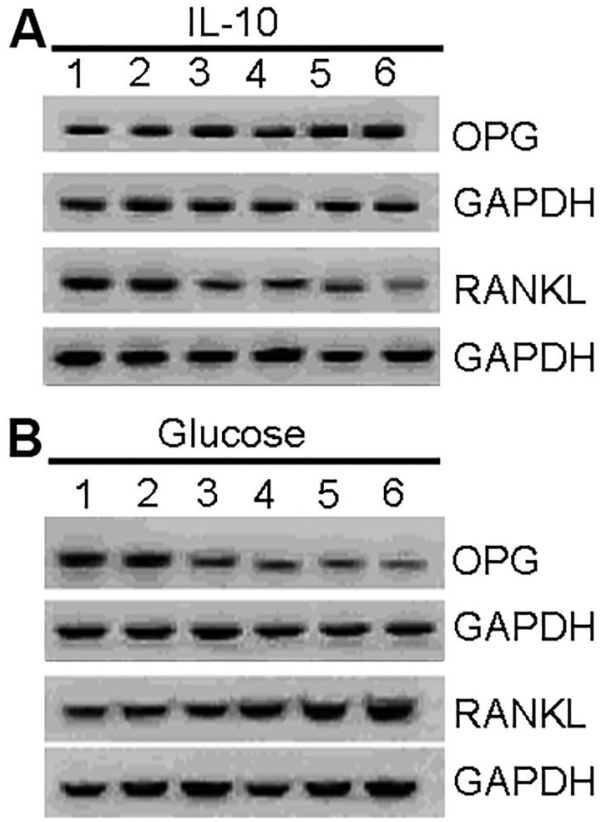

Figure 3. Effects of $\mathrm{IL}-10(A)$ and glucose $(B)$ at different concentrations on the protein expression of osteoprotegerin (OPG) and receptor activator of nuclear factor- $\kappa B$ ligand (RANKL) in human periodontal ligament fibroblasts. Panel $A$, lanes 1-6: cells treated with interleukin-10 (IL-10) at $0,1,10,25,50$, and $100 \mathrm{ng} / \mathrm{mL}$, respectively. Panel B, lanes 1-6: cells treated with glucose at $0,5.5,10,20,30$, and $40 \mathrm{mmol} / \mathrm{L}$, respectively. GAPDH: anti-glyceraldehyde-3-phosphate dehydrogenase.

progression of periodontal disease (16). OPG has the ability to inhibit osteoclast differentiation and bone resorption, and induce apoptosis of mature osteoclasts (17). Accordingly, OPG knockout mice display a severe reduction in bone mineral density because of osteoclast activation and increased bone resorption (18), whereas OPG transgenic mice exhibit an increase in bone mineral density (19). RANKL promotes bone resorption by enhancing osteoclast motility and inhibiting apoptosis (20). Under normal physiological conditions, OPG is expressed more highly than RANKL in HPDLFs, which promotes stabilization of the periodontal tissue (21). In periodontal disease, the expression of RANKL increases relative to that of OPG, resulting in periodontal tissue destruction $(22,23)$. Data from the present study demonstrate that above-physiological glucose levels induced significant changes in OPG and RANKL expression in HDPLFs. Upregulation of RANKL under high glucose conditions has also been described in human periodontal ligament cells (24). García-Hernández et al. (9) reported that glucose stimulation increased mRNA expression of RANKL and decreased mRNA expression of OPG in human osteoblastic cells. These findings may provide an explanation for exacerbation of periodontal disease by diabetesassociated hyperglycemia.

The pathogenesis of diabetes is associated with changes in the production of anti- and pro-inflammatory cytokines. IL-10, as a pivotal anti-inflammatory cytokine, is usually downregulated during the development of diabetes (10). IL-10 has the ability to downregulate the synthesis of pro-inflammatory cytokines, including tumor necrosis factor- $\alpha$ (TNF- $\alpha$ ), IL-1 $\beta$, IL-6, and IL-8 (25). IL-1 $\beta$ has been shown to upregulate RANKL expression in human periodontal ligament cells (26). The combination of TNF- $\alpha$ and IL-6 has been reported to induce mouse osteoclast-like cells with bone resorption activity (27), suggesting that IL-10 has a favorable role in bone formation. Indeed, IL-10 knockout mice had significant alveolar bone loss compared with wild-type mice (9). In the present study, IL-10 caused concentration-dependent upregulation of OPG expression in HPDLFs. Conversely, RANKL expression was concentration-dependently reduced in IL-10-treated HPDLFs. These results confirm the involvement of IL-10 in bone remodeling pathways. A previous study reported that injection of IL-10 to HuPBL-NOD/SCID rats infected by Actinomyces resulted in significantly less alveolar bone resorption (28). Local delivery of exogenous IL-10 may represent a potential treatment for periodontal disease.

This study has a few limitations. Of note, the signaling pathways that mediate regulation of OPG and RANKL by glucose and IL-10 remain to be clarified. In addition, the

Table 3. Relative protein expression of osteoprotegerin (OPG) and receptor activator of nuclear factor- $\mathrm{K} B$ ligand (RANKL) in human periodontal ligament fibroblasts after interleukin-10 (IL-10) or glucose treatment.

\begin{tabular}{cccccc}
\hline IL-10 $(\mathrm{ng} / \mathrm{mL})$ & OPG & RANKL & Glucose $(\mathrm{mmol} / \mathrm{L})$ & OPG & RANKL \\
\hline 0 & $0.790 \pm 0.010^{\mathrm{a}}$ & $0.794 \pm 0.007^{\mathrm{a}}$ & 0 & $0.835 \pm 0.016^{\mathrm{a}}$ & $0.707 \pm 0.017^{\mathrm{a}}$ \\
1 & $0.977 \pm 0.009^{\mathrm{b}}$ & $0.840 \pm 0.015^{\mathrm{b}}$ & 5.5 & $0.980 \pm 0.019^{\mathrm{b}}$ & $0.733 \pm 0.018^{\mathrm{a}}$ \\
10 & $1.148 \pm 0.018^{\mathrm{c}}$ & $0.713 \pm 0.019^{\mathrm{c}}$ & 10 & $0.637 \pm 0.013^{\mathrm{c}}$ & $0.865 \pm 0.019^{\mathrm{b}}$ \\
25 & $1.186 \pm 0.012^{\mathrm{d}}$ & $0.637 \pm 0.017^{\mathrm{d}}$ & 20 & $0.519 \pm 0.016^{\mathrm{d}}$ & $1.025 \pm 0.017^{\mathrm{c}}$ \\
50 & $1.211 \pm 0.010^{\mathrm{e}}$ & $0.604 \pm 0.019^{\mathrm{e}}$ & 30 & $0.427 \pm 0.018^{\mathrm{e}}$ & $1.366 \pm 0.012^{\mathrm{d}}$ \\
100 & $1.253 \pm 0.014^{\mathrm{f}}$ & $0.429 \pm 0.018^{\mathrm{f}}$ & 40 & $0.382 \pm 0.013^{\mathrm{f}}$ & $1.204 \pm 0.010^{\mathrm{e}}$ \\
\hline
\end{tabular}

Data are reported as means $\pm S D$. Different superscript letters indicate significant differences $(P<0.05$; ANOVA followed by Tukey's multiple comparison). 
combined effect of glucose and IL-10 on expression of OPG and RANKL is not known.

To conclude, high concentrations of glucose upregulated RANKL and downregulated OPG, whereas IL-10 produced opposing effects to those of high glucose in HPDLFs. These findings warrant further investigation of the effect of glucose on the expression of OPG and RANKL, and on bone remodeling in periodontal disease.

\section{References}

1. Katagiri T, Takahashi N. Regulatory mechanisms of osteoblast and osteoclast differentiation. Oral Dis 2002; 8: 147-159, doi: 10.1034/j.1601-0825.2002.01829.x.

2. Valverde $P$, Kawai T, Taubman MA. Selective blockade of voltage-gated potassium channels reduces inflammatory bone resorption in experimental periodontal disease. J Bone Miner Res 2004; 19: 155-164, doi: 10.1359/jbmr.0301213.

3. Zhao L, Chen J, Cheng L, Wang X, Du J, Wang F, et al. Effects of Enterococcus faecalis lipoteichoic acid on receptor activator of nuclear factor-kappaB ligand and osteoprotegerin expression in periodontal ligament fibroblasts. Int Endod $J$ 2014; 47: 163-172, doi: 10.1111/iej.12127.

4. Hasegawa T, Yoshimura Y, Kikuiri T, Yawaka Y, Takeyama S, Matsumoto $A$, et al. Expression of receptor activator of NF-kappa B ligand and osteoprotegerin in culture of human periodontal ligament cells. J Periodontal Res 2002; 37 : 405-411, doi: 10.1034/j.1600-0765.2002.01603.x.

5. Casanova L, Hughes FJ, Preshaw PM. Diabetes and periodontal disease: a two-way relationship. $\mathrm{Br}$ Dent $J$ 2014; 217: 433-437, doi: 10.1038/sj.bdj.2014.907.

6. Al-Rasheed A, Scheerens H, Rennick DM, Fletcher HM, Tatakis DN. Accelerated alveolar bone loss in mice lacking interleukin-10. J Dent Res 2003; 82: 632-635, doi: 10.1177/ 154405910308200812.

7. Schwartz AV. Diabetes Mellitus: Does it Affect Bone? Calcif Tissue Int 2003; 73: 515-519, doi: 10.1007/s00223-0030023-7.

8. Engebretson S, Chertog R, Nichols A, Hey-Hadavi J, Celenti R, Grbic J. Plasma levels of tumour necrosis factor-alpha in patients with chronic periodontitis and type 2 diabetes. J Clin Periodontol 2007; 34: 18-24, doi: 10.1111/j.1600-051X.2006. 01017.x.

9. García-Hernández A, Arzate H, Gil-Chavarria I, Rojo R, Moreno-Fierros L. High glucose concentrations alter the biomineralization process in human osteoblastic cells. Bone 2012; 50: 276-288, doi: 10.1016/j.bone.2011.10.032.

10. van Exel E, Gussekloo J, de Craen AJ, Frolich M, Bootsmavan der Wiel A, Westendorp RG. Low production capacity of interleukin-10 associates with the metabolic syndrome and type 2 diabetes : the Leiden 85-Plus Study. Diabetes 2002; 51: 1088-1092, doi: 10.2337/diabetes.51.4.1088.

11. Rincon JC, Haase HR, Bartold PM. Effect of Emdogain on human periodontal fibroblasts in an in vitro wound-healing model. J Periodontal Res 2003; 38: 290-295, doi: 10.1034/ j.1600-0765.2003.00610.x.

12. Morandini AC, Sipert CR, Ramos-Junior ES, Brozoski DT, Santos CF. Periodontal ligament and gingival fibroblasts participate in the production of TGF-beta, interleukin (IL)-8 and IL-10. Braz Oral Res 2011; 25: 157-162, doi: 10.1590/ S1806-83242011000200010.

13. Nishimura F, Terranova V, Foo H, Kurihara M, Kurihara $H$, Murayama Y. Glucose-mediated alteration of cellular function in human periodontal ligament cells. J Dent Res 1996; 75: 1664-1671, doi: 10.1177/00220345960750090801.

14. Bascones-Martinez A, Gonzalez-Febles J, Sanz-Esporrin J. Diabetes and periodontal disease. Review of the literature. Am J Dent 2014; 27: 63-67.

15. Soskolne WA. Epidemiological and clinical aspects of periodontal diseases in diabetics. Ann Periodontol 1998; 3: 3-12, doi: 10.1902/annals.1998.3.1.3.

16. Ciantar M, Spratt DA, Newman HN, Wilson M. Development of an in vitro microassay for glucose quantification in submicrolitre volumes of biological fluid. J Periodontal Res 2002; 37: 79-85, doi: 10.1034/j.1600-0765.2001.00313.x.

17. Sakata M, Shiba H, Komatsuzawa H, Fujita T, Uchida $Y$, Yoshino $\mathrm{H}$, et al. Osteoprotegerin levels increased by interleukin-1beta in human periodontal ligament cells are suppressed through prostaglandin $E(2)$ synthesized de novo. Cytokine 2002; 18: 133-139, doi: 10.1006/cyto.2002. 1026.

18. Bucay N, Sarosi I, Dunstan CR, Morony S, Tarpley J, Capparelli C, et al. Osteoprotegerin-deficient mice develop early onset osteoporosis and arterial calcification. Genes Dev 1998; 12: 1260-1268.

19. Koide M, Kobayashi $Y$, Ninomiya T, Nakamura M, Yasuda H, Arai $Y$, et al. Osteoprotegerin-deficient male mice as a model for severe alveolar bone loss: comparison with RANKLoverexpressing transgenic male mice. Endocrinology 2013; 154: 773-782, doi: 10.1210/en.2012-1928.

20. Dougall WC, Glaccum M, Charrier K, Rohrbach K, Brasel K, De Smedt T, et al. RANK is essential for osteoclast and lymph node development. Genes Dev 1999; 13: 2412-2424.

21. Zhang L, Zhou X, Wang Q, Wang Y, Tang L, Huang D. Effect of heat stress on the expression levels of receptor activator of NF-kappaB ligand and osteoprotegerin in human periodontal ligament cells. Int Endod $J$ 2012; 45: 68-75, doi: 10.1111/j.1365-2591.2011.01949.x.

22. Wada N, Maeda H, Tanabe K, Tsuda E, Yano K, Nakamuta $\mathrm{H}$, et al. Periodontal ligament cells secrete the factor that inhibits osteoclastic differentiation and function: the factor is osteoprotegerin/osteoclastogenesis inhibitory factor. J Periodontal Res 2001; 36: 56-63, doi: 10.1034/j.1600-0765. 2001.00604.x.

23. Dereka XE, Markopoulou CE, Fanourakis G, TseleniBalafouta S, Vrotsos IA. RANKL and OPG mRNA level after non-surgical periodontal treatment. Inflammation 2010; 33: 200-206, doi: 10.1007/s10753-009-9174-7.

24. Feng $\mathrm{Y}$, Liu JQ, Liu HC. AMP-activated protein kinase acts as a negative regulator of high glucose-induced RANKL expression in human periodontal ligament cells. Chin Med J 2012; 125: 3298-3304.

25. de Waal Malefyt R, Abrams J, Bennett B, Figdor CG, de Vries JE. Interleukin 10(IL-10) inhibits cytokine synthesis by human monocytes: an autoregulatory role of IL-10 produced 
by monocytes. J Exp Med 1991; 174: 1209-1220, doi: 10.1084/jem.174.5.1209.

26. Wu LZ, Duan DM, Liu YF, Ge X, Zhou ZF, Wang XJ. Nicotine favors osteoclastogenesis in human periodontal ligament cells co-cultured with CD4 $(+)$ T cells by upregulating IL-1beta. Int $J$ Mol Med 2013; 31: 938-942, doi: 10.3892/ijmm.2013.1259.

27. Yokota K, Sato K, Miyazaki T, Kitaura H, Kayama H, Miyoshi $F$, et al. Combination of tumor necrosis factor alpha and interleukin-6 induces mouse osteoclast-like cells with bone resorption activity both in vitro and in vivo. Arthritis Rheumatol 2014; 66: 121-129, doi: 10.1002/art.38218.

28. Zhang $X$, Teng YT. Interleukin-10 inhibits gram-negativemicrobe-specific human receptor activator of NF-kappaB ligand-positive CD4 +-Th1-cell-associated alveolar bone loss in vivo. Infect Immun 2006; 74: 4927-4931, doi: 10.1128/ IAl.00491-06. 